\title{
Testing for exceptional bulls and bears: a non- parametric perspective
}

Citation for published version (APA):

Candelon, B., \& Metiu, N. (2009). Testing for exceptional bulls and bears: a non-parametric perspective. METEOR, Maastricht University School of Business and Economics. METEOR Research Memorandum No. 017 https://doi.org/10.26481/umamet.2009017

Document status and date:

Published: 01/01/2009

DOI:

10.26481/umamet.2009017

Document Version:

Publisher's PDF, also known as Version of record

\section{Please check the document version of this publication:}

- A submitted manuscript is the version of the article upon submission and before peer-review. There can be important differences between the submitted version and the official published version of record.

People interested in the research are advised to contact the author for the final version of the publication, or visit the DOI to the publisher's website.

- The final author version and the galley proof are versions of the publication after peer review.

- The final published version features the final layout of the paper including the volume, issue and page numbers.

Link to publication

\footnotetext{
General rights rights.

- You may freely distribute the URL identifying the publication in the public portal. please follow below link for the End User Agreement:

www.umlib.nl/taverne-license

Take down policy

If you believe that this document breaches copyright please contact us at:

repository@maastrichtuniversity.nl

providing details and we will investigate your claim.
}

Copyright and moral rights for the publications made accessible in the public portal are retained by the authors and/or other copyright owners and it is a condition of accessing publications that users recognise and abide by the legal requirements associated with these

- Users may download and print one copy of any publication from the public portal for the purpose of private study or research.

- You may not further distribute the material or use it for any profit-making activity or commercial gain

If the publication is distributed under the terms of Article $25 \mathrm{fa}$ of the Dutch Copyright Act, indicated by the "Taverne" license above, 


\section{Maastricht University}

Bertrand Candelon, Norbert Metiu

Testing for Exceptional Bulls and Bears: a Non-Parametric Perspective

RM/09/017

\section{METEOR}

Faculty of Economics and Business Administration Maastricht Research School of Economics

of Technology and Organization

P.O. Box 616

NL - 6200 MD Maastricht

The Netherlands 


\title{
Testing for Exceptional Bulls and Bears: a Non-Parametric Perspective.
}

\author{
Bertrand Candelon ${ }^{* \dagger} \quad$ Norbert Metiu ${ }^{\ddagger \S}$
}

April 21, 2009

\begin{abstract}
This paper investigates exceptional phases of stock market cycles. Defined in Pagan and Sossounov (2003) as unusual, they are detected as outliers in the historical distribution. Moreover, this study completes the growing literature on stock market bulls and bears in several aspects. First,it extends the description of financial cycles by going beyond solely the duration feature. Second, a new strategy to test for single and multiple outliers is presented. Based on this procedure, the exceptional bulls and bears that occurred since 1973 are detected. A complementary analysis deals with the specific cross-country patterns of the current sub-prime crisis. Our results are mixed, in the sense that they do not support the idea that the ongoing bear is exceptional for all the analyzed countries. Moreover, the results indicate that the stock market indices are still far away from the thresholds beyond which the current bear phase will become exceptional worldwide.
\end{abstract}

J.E.L. Codes: C19; E32; F36

Keywords: Financial crisis; Financial cycles; Non-Parametric method; Outlier.

\footnotetext{
*Corresponding author: Tel:+31 (0)433883442, Fax: $\quad+31 \quad$ (0)433884864, Email: b.candelon@algec.unimaas.nl.

$\dagger$ Address: Maastricht University, Department of Economics, PO Box 616, 6200 MD, Maastricht, The Netherlands.

${ }^{\ddagger}$ Maastricht University, Department of Economics, PO Box 616, MD 6200, Maastricht, The Netherlands.

$\S$ The authors thank Don Harding, Jan Piplack and Tyas Prevoo, as well as the participants of the internal seminar at the University Roma-Tor Vergata for comments and remarks. Usual disclaimers apply.
} 


\section{Introduction}

Since 2007, the world economy is in strong financial distress, resulting in the collapse of real estate markets, the destabilization of the international banking system paired with the bankruptcy of several financial institutions (e.g. Lehmann Brothers), as well as the beginning of a bear period on most of the world's stock exchanges. In a seminal paper, Reinhart and Rogoff (2008) analyze the specificities and the similarities of the ongoing sub-prime crisis for the United States, when compared to the international financial strains which affected the U.S. during the last 30 years. It turns out that even if all crises have been preceded by a de facto liberalization, the sub-prime crisis has distinct features, such as deflation, or a Balance of Payment surplus in emerging market countries. Naturally, one may expect that these peculiarities would translate into stock market characteristics. For example, it is likely that the sub-prime crisis affects the volatility of stock market indices by introducing a new cluster and/or a new regime of high volatility. Similarly, the huge variation in stock market returns surely modifies the heavy tail properties of stock markets.

It is also probable that the sub-prime crisis has some consequences for "bull" and "bear" phases. These empirical stylized facts illustrate the periods of persistent rises (bulls) or falls (bears) observed on the stock market. As the concept of bulls and bears seems to rely on soft theoretical grounds ${ }^{1}$, for a long time it has been neglected by the academic community. Only recently empirical studies have shown the undoubtable importance of bulls and bears in better grasping the evolution of stock markets. ${ }^{2}$

At the same time, practitioners, who mainly use charts to determine their positions, have always found the information on bulls and bears valuable to build optimal portfolios.

\footnotetext{
${ }^{1}$ Traditionally, two perspectives can explain the presence of persistent rises or falls in stock prices. First, they may be caused by irrational "animal spirit", i.e. decision patterns that are unrelated to any rational expectations of future fundamental values, see e.g. Summers (1986), Shiller (2000) or Anderson et al. (2003). According to this perspective, prices can sometimes display seemingly persistent deviations from their long run equilibrium values. Another view states that, although market sentiments can drive away prices quite substantially from fundamentals in the short run, proportional differences between market prices and fundamentals are kept within bounds, and stock market prices do obey a long run relation with fundamentals, see e.g. Barsky and De Long (1990), Siegel (1998) or Coakley and Fuertes (2006). This paper does not fit in either of these two strands of literature, as we do not aim to disentangle the causes of stock market bulls and bears.

${ }^{2}$ Pagan and Sossounov (2003), and Candelon et al. (2008) scan the cross country synchronization of bull and bear phases. Gómez Biscarri and Pérez de Gracia (2002), and Edwards et al. (2003) focus on the structural change in cyclical stock market synchronization. Chen (2009) considers bear markets as a key variable to forecast, and investigates the role of macroeconomic variables to predict bear markets.
} 
Typically, investors adjust their portfolios by buying "cheap" stocks during bear phases, and by selling "expensive" stocks during bull periods. The stability of cyclical fluctuation on stock markets is the guaranty for investors that their decisions are rational and their returns are optimal. Besides, they are also using ex-post information on financial cycles to set up forecasts. In this regard, knowing whether the sub-prime crisis induces a modification in financial cycles or not, is a key question. If the crisis does not modify the shape of the ongoing bear period, it is then possible for the investors to anticipate the end of the bear phase, and to position themselves adequately with respect to the coming upswing, using traditional charts. The bear will then be regular, hence potentially forecastable. On the contrary, if the recent bear phase is irregular, i.e. with exceptional characteristics, inference from past observations is impossible. In this case, the future evolution in stock markets remains uncertain, leading most investors to freeze or to close their positions until the end of this exceptional phase. Therefore, investigating irregularities, or exceptional bulls and bears, turns out to be crucial.

Several approaches have been proposed to measure extreme events. The Extreme Value Theory (EVT) evaluates the risks of loss associated with stock market returns. It focuses on the estimation of a tail index $\alpha$, representing the degree of probability mass in the tail. ${ }^{3}$ It is then possible to derive the Value-at-Risk for a particular size (usually $1 \%$ or $5 \%$ ), indicating the limit value beyond which a return becomes extreme. In the context of financial cycles, Pagan and Sossounov (2003) propose an alternative concept of extreme events. They define exceptional (or extreme) cycles as "unusual" phases differing from "usual" ones in that they are not issued from the same Data Generating Process (DGP). A straightforward strategy consists then in detecting outliers in the historical distribution, and in associating them with exceptional (or extreme) events. ${ }^{4}$ Nevertheless, as underlying $D G P$ s are unknown, non-parametric tests should be preferred to parametric ones. While the link between both approaches to measuring extreme events is well-known, this paper adopts the framework of Pagan and Sossounov (2003), as it is specifically designed for the analysis of financial cycles.

In addition to measuring exceptional financial cycles, the characterization of bull and

\footnotetext{
${ }^{3}$ See Jansen and de Vries (1991), Longin (1996), Lux (1996) and Hartmann et al. (2004) for applications of the probability mass in the tails of stock market returns.

${ }^{4}$ Pagan and Sossounov (2003) do not explicitly consider outlier detection. However, they attempt to explain movements in the actual stock prices by determining the likelihood of extreme cycles being generated by a particular simulated model. This approach implicitly corresponds to the identification of extreme bulls and bears as outliers with respect to a predefined DGP.
} 
bear periods, as well as a thorough analysis of the latest sub-prime crisis also constitute the aim of the present study. More precisely, this paper contributes to the literature on the cyclical behavior of stock markets in four ways. First, it does not exclusively focus on the time spent in each phase (i.e. duration), but takes also other key features of bull and bear phases into consideration, which may help investors determine the share of the portfolio that should be reshuffled during these periods. The measures taken into account include the amplitude, the cumulated returns, and the excess returns. Second, elaborating on Singh and Xie (2003), and Silverman (1981), we propose a new non-parametric procedure to test for the presence of outliers in a sample issued from an unknown probability distribution. This procedure allows us to extract the unusual bull and bear phases, i.e. those which exhibit exceptional features, and therefore are not issued from the same distribution. Third, this paper completes the analysis of Reinhart and Rogoff (2008), by examining the cross-country exceptionality of the sub-prime crisis. By comparing the outcomes of the proposed procedure, with or without censoring for the latest bear period (the one associated with the ongoing turmoil), it is possible to shed some light on the effects of the crisis on stock market indices of nine OECD countries. Finally, when applied in a normative fashion, the non-parametric method provides thresholds beyond which the crisis would become extraordinary, if it is not already the case. Hence, our analysis will offer investors guidelines for an adequate portfolio management, depending on whether these thresholds have or have not been crossed.

Anticipating on our conclusion, it is possible to state that the ongoing sub-prime crisis has not lead to an exceptional bear yet worldwide, as up-to-date, only the bear markets of Austria, the Netherlands, the United Kingdom, and the United States appear to be extreme. Moreover, it is noticeable that most stock markets are still far away from the thresholds beyond which the current bear phase will become extraordinary, and the chance of these thresholds being crossed in the near future is moderate.

The paper commences with the presentation of the method which is subsequently used to detect outliers in the distribution of bull and bear characteristics. In Section 3 a Monte Carlo exercise is performed in order to investigate the statistical properties of this new approach. In Section 4 the empirical analysis of stock market indices in nine OECD countries is presented. Section 5 concludes. 


\section{A Non-Parametric Sequential Approach for De- tecting Outlier(s)}

\subsection{A Bootstrap Based Outlier Detection Plot}

Let us consider a sample $\mathbf{Y}=\left[Y_{1}, \ldots, Y_{n}\right]$ of $n$ observations for a particular feature of the stock market cycle, observed in a particular country. The underlying distribution generating this sequence is unknown. Following Pagan and Sossounov (2003), the characteristic of the cycle $i\left(Y_{i}\right)$ is exceptional (or extreme) if the DGP generating it differs from the one underlying $Y_{j}$, where $j=1, \ldots, n$ and $j \neq i$. $Y_{i}$ appears as an outlier in the empirical distribution of $\mathbf{Y}$.

Singh and Xie (2003) propose a Bootstrap Based Outlier Detection Plot (or Bootlier) method as a graphical tool to detect the presence of outlier(s) in such a framework. Let us consider the bootstrap sample $\mathbf{Y}^{*}=\left[Y_{1}^{*}, \ldots, Y_{n}^{*}\right]$ obtained from $\mathbf{Y}$. It is possible to calculate the "mean-trimmed mean" ( $M T M$ hereafter) of $\mathbf{Y}^{*}$ as follows:

$$
\operatorname{MTM}\left(\mathbf{Y}^{*}\right)=\frac{1}{n} \sum_{i=1}^{n} Y_{i}^{*}-\frac{1}{n-2 k} \sum_{i=k+1}^{n-k} Y_{(i)}^{*},
$$

where $k$ is the trimming value and $Y_{(i)}^{*}$ are the order statistics. $M T M\left(\mathbf{Y}^{*}\right)$ corresponds to subtracting the $k$-trimmed mean from the arithmetic mean of the bootstrap sample. Singh and Xie (2003) prove that in presence of outlier(s) the histogram of $M T M\left(\mathbf{Y}^{*}\right)$ is characterized by several modes. The intuition behind such a property is straightforward: it is well-known ${ }^{5}$ that the $k$-trimmed mean - the second term on the right-hand side of (1) - provides a transitory estimator between the mean and the median in terms of sensitivity, since it is computed by taking the mean when $k$ extreme values are trimmed from each side of the distribution. ${ }^{6}$ Therefore, when subtracting the $k$-trimmed mean from the arithmetic mean of the bootstrap sample, one obtains an estimator that puts more emphasis on extremes, thereby making the bootstrap histogram of $\operatorname{MTM}\left(\mathbf{Y}^{*}\right)$ sensitive to the presence of outlier(s). Consequently, since only a certain fraction of the bootstrap sample $\mathbf{Y}^{*}$ contains the outlier(s), the bootstrap histogram of $M T M\left(\mathbf{Y}^{*}\right)$ should exhibit one mode associated with the distribution of $\mathbf{Y}^{*}$, and at least another one corresponding

\footnotetext{
${ }^{5}$ See e.g. Casella and Berger (2002).

${ }^{6}$ It is possible to show that the distribution of the $k$-trimmed mean is asymptotically normal.
} 
to the outlier(s). ${ }^{7}$ Thus, testing for the presence of outlier(s) in $\mathbf{Y}$ boils down to testing for unimodality of the density $f($.$) of M T M\left(\mathbf{Y}^{*}\right)$.

Three issues need to be addressed with respect to the Bootlier approach. Firstly, the choice of the trimming value $k$ is of great importance. Singh and Xie (2003) do not provide theoretical justification for the choice of $k$, and decide to fix it to $k=2$ independently of the sample size $n$. It is straightforward that the larger $k$ will be, the more unimodal the density function will be. ${ }^{8}$ Secondly, it should be noted that the number of modes does not necessarily match the number of outliers. Typically, several outliers of the same magnitude will be located around the same pole and only one mode will appear in $f($.$) . It is thus$ not correct to associate a given number of outliers with the same number of modes in the density $f($.$) of \operatorname{MTM}\left(\mathbf{Y}^{*}\right)$. Finally, Singh and Xie (2003) introduce a Bootlier index, as a rule-of-thumb tool in order to determine the degree of bumpiness of the density function, but they do not provide a statistical framework to test for unimodality, and thus for the presence of outliers. They state that "Formal tests for outliers can be constructed with the bi [Bootlier index] as test statistic under a distributional assumption" (Singh and Xie (2003), page 543.). Furthermore, their approach relies on several distance measures, such as the Mahalanobis distance, which are not suitable for small sample sizes. ${ }^{9}$

Our approach proposes to extend the Bootlier method in order to tackle the above mentioned criticisms. The idea consists of coupling it with a non-parametric test for modality, which will allow us to conduct a formal test for the presence of multiple outliers without a distributional assumption.

\subsection{Testing for Unimodality}

A formal test for the presence of an outlier can be constructed from the following hypothesis:

\footnotetext{
${ }^{7}$ Singh and Xie (2003) show that asymptotically the limiting bootstrap $M T M$ distribution can be expressed as a mixture of normal distributions. Therefore, if there is a minimum amount of separation between the outlier(s) and the remainder of the sample, then the mixture density (the Bootlier plot) will be multimodal. We explore the degree of separation in our Monte Carlo experiment in Section 3, by introducing outlier(s) of different magnitudes into the baseline $D G P$.

${ }^{8}$ Since in the empirical application typically 10 financial cycles are observed, $k$ should remain relatively small. Moreover, simulations have shown that the power of our test is maximal for $k=1$. We thus retain a trimming value of 1 in the rest of the paper. Nevertheless, a robustness check with $k=2$ shows that outcomes remain unchanged. Results are available from the authors upon request.

${ }^{9}$ See Barnet and Lewis (1994) for a survey of distance measures in the context of outlier(s) detection and finite sample.
} 


$$
\left\{\begin{array}{l}
H_{0}: f\left(M T M\left(\mathbf{Y}^{*}\right)\right) \text { has precisely one mode, } \\
H_{1}: f\left(M T M\left(\mathbf{Y}^{*}\right)\right) \text { has more than one mode }
\end{array}\right.
$$

in the interior of a given closed interval $\Im$.

The seminal test for the modality of a density function corresponding to an unknown distribution has been proposed by Silverman (1981). A consistent estimate of $f(x)$ is the kernel density estimator $\hat{f}_{h}(x)$ :

$$
\hat{f}_{h}=\frac{1}{n h} \sum_{i=1}^{n} K\left(\frac{x-X_{i}}{h}\right),
$$

where $h$ is a bandwidth, and $K($.$) a kernel function, furthermore X_{i}$ denotes the $\operatorname{MTM}\left(\mathbf{Y}^{*}\right)$ statistic of the $i^{t h}$ bootstrap sample, $M T M_{i}$. As in Silverman (1981), $K($.$) is chosen to$ be the standard normal density function. This choice is motivated by the fact that for standard normal $K($.$) , the number of modes in \hat{f}_{h}$ is a right continuous decreasing function of $h$. Moreover, if $h$ is sufficiently large, $\hat{f}_{h}$ will have a single mode in the interior of the given closed interval $\Im$. It is then possible to find the narrowest bandwidth $\hat{h}_{\text {crit }}$ for the density $f($.$) , for which \hat{f}_{h_{c r i t}}$ is unimodal. In other words, the critical bandwidth is defined as $\hat{h}_{\text {crit }}=\inf \left(h ; \hat{f}_{h}\right.$ has precisely one mode in $\left.\Im\right)$. It is straightforward that $\hat{h}_{\text {crit }}$ will be larger for a multimodal density function than for a unimodal one. Silverman (1981) proposes a bootstrap procedure, which exploits this feature to test for the unimodality of $f($.$) :$

- Step A. Fit the kernel density estimate in (3) on the $M T M\left(\mathbf{Y}^{*}\right)$, and determine $\hat{h}_{\text {crit }}$ and thus $\hat{f}_{\text {hcrit }}$.

- Step B.1. Let $\left[M T M_{1}^{*}, \ldots, M T M_{n}^{*}\right]$ be a resample drawn from the distribution with density $\hat{f}_{h_{\text {crit }}} \cdot{ }^{10}$

- Step B.2. Build $\hat{f}_{h}^{*}=\frac{1}{n h} \sum_{i=1}^{n} K\left(\frac{x-M T M_{i}^{*}}{h}\right)$.

\footnotetext{
${ }^{10}$ In practice we have corrected the bootstrap samples to have the same first and second moments as those observed in the original sample, following Efron (1979):

$$
M T M_{i}^{*}=\overline{M T M^{b *}}+\left(M T M_{i}^{b *}-\overline{M T M^{b *}}+\hat{h}_{c r i t} \varepsilon_{i}\right)\left(1+\hat{h}_{c r i t} / \sigma_{M T M\left(\mathbf{Y}^{*}\right)}^{2}\right)^{-\frac{1}{2}}
$$

where $\varepsilon_{i}$ is an i.i.d variable issued from the density $K(),. \sigma_{M T M\left(\mathbf{Y}^{*}\right)}^{2}$ denotes the variance of $M T M\left(Y^{*}\right)$, while $b$ stands for uncorrected values of the bootstrap sample.
} 
- Step B.3. Determine $h_{c r i t}^{*}$ for $\hat{f}_{h_{c r i t}}$, as well as $h_{c r i t}^{*} / \hat{h}_{c r i t}$.

- Step C. Repeat Steps B.1. to B.3. a large number of times. The null hypothesis of unimodality is rejected if $\operatorname{Prob}\left(h_{\text {crit }}^{*} / \hat{h}_{\text {crit }} \leq \lambda_{\alpha}\right) \geq 1-\alpha, \alpha$ being the nominal size usually fixed to $5 \%$.

The choice of the scaling parameter $\lambda_{\alpha}$ is of concern, even if it is generally fixed to 1 . However, Hall and York (2001) showed that this assumption leads to an excessively low size, which results in over-accepting the null hypothesis of unimodality, and they calibrate $\lambda_{\alpha}$ for level accuracy arising from non-uniformity of the distribution. Hall and York (2001) prove the validity of the bootstrap procedure, and its ability to tackle the finite sample bias. Fisher and Marron (2001) show that problems arise when the underlying distribution is heavy tailed. In such a case two additional tuning parameters (the so-called "minimum level parameter" and "minimum mass parameter") are introduced, which allow for a certain degree of flexibility in defining modes in terms of their strength. It then turns out that in empirical studies particular attention has to be paid to the optimal determination of $\lambda_{\alpha}$.

\subsection{A Sequential Approach to Test for Multiple Outliers}

Coupling the Bootlier approach with Silverman's modality test leads to a non-parametric strategy of determining the presence of an outlier. Given the original sample $\mathbf{Y}=$ $\left[Y_{1}, \ldots, Y_{n}\right]$, this approach requires deriving the statistic $M T M\left(\mathbf{Y}^{*}\right)$, and then the bootstrap test for modality described in the previous subsection is performed. Hereafter we will refer to this procedure as the BootS test.

We propose to apply the BootS test in a sequential fashion so as to identify the presence of multiple outliers in $\mathbf{Y}$. For this purpose, rolling samples $\mathbf{R S}_{j}=\left[Y_{(j)}, Y_{(j+1)}, \ldots, Y_{(j+u-1)}\right]$ are issued from $\mathbf{Y}_{(i)} .{ }^{11}$ The dimension of each $\mathbf{R} \mathbf{S}_{j}$ is $u$ (where $u \leq n$ ), and the number of rolling samples corresponds to $j=1, \ldots, n+1-u$. The parameter $u$ is chosen starting with the largest $u(u=n)$, which implies that $j=1$, and the BootS test is conducted for the largest rolling sample $\mathbf{R S}_{1}=\mathbf{Y}_{(i)}$. Thus, in the first step the entire sample of order statistics is analyzed. If the null hypothesis of unimodality of $\hat{f}_{h}(x)$ (where $x$ corresponds to $\left.\operatorname{MTM}\left(\mathbf{R S}_{1}^{*}\right)\right)$ is rejected, hence the presence of outlier(s) in $\mathbf{Y}$ is supported, then $u$ is

\footnotetext{
${ }^{11}$ We recall that $\mathbf{Y}_{(i)}$ is the vector of order statistics $\mathbf{Y}_{(i)}=\left[Y_{(1)}, \ldots, Y_{(n)}\right]$.
} 
decreased sequentially, one by one. ${ }^{12}$ The BootS test is repeated for the rolling samples of decreased dimension, until the null hypothesis fails to be rejected. Once unimodality is confirmed for at least one rolling sample for a particular $u^{\prime}$, then the sequential procedure stops, and it is possible to merge the rolling samples that exhibit unimodality, and which overlap in at least one order statistic. It follows that the subsample $\mathbf{Y}_{u^{\prime} \leq n}$ spanned by the merged rolling samples, is generated by the same underlying DGP. The complementary sample $\mathbf{Y}_{n \neq u^{\prime}}$ will contain the outlier(s), and the number of outlier(s) will be $n-u^{\prime}$.

\section{Monte Carlo Simulations}

In this section we set up simulation experiments in order to investigate the behavior of the BootS procedure, stressing three specific points.

First, Hall and York (2001) show that Silverman's test is strongly undersized when $\lambda_{\alpha}=1$. This statistical property would lead to accepting the null hypothesis of no outlier too often, which can be problematic for empirical applications. Second, Fisher and Marron (2001) stress that this bias is particularly important when the DGP exhibits fat tails. As we do not have any pre-knowledge on the heavy tail properties of the financial cycle characteristics, it is necessary to consider two different $D G P$ s for the exercise. ${ }^{13}$ The first one (denominated "DGP.") is the standard normal distribution, which is not skewed. For the second $D G P$ (denominated " $D G P_{2}$ ") we opted for the Student-t distribution. Besides being one of the most popular distributions to mimic financial time series patterns, it has an extreme mass on the right tail. ${ }^{14}$ Finally, in our empirical application we can not rely on asymptotic properties as the number of financial cycles are rather limited. Two sample sizes are therefore considered in the simulations: one mimics the number of observations we will typically encounter in our empirical applications (i.e. $n=10$ ), while the other one corresponds to the asymptotic sample size, and for ease of computer time it is fixed to $n=100$.

\footnotetext{
${ }^{12}$ Note, that in the second step $u=n-1$, therefore $j=1,2$, which implies that there are two rolling samples, furthermore, in the third step $u=n-2$, therefore $j=1,2,3$, and there are three rolling samples, and so on.

${ }^{13}$ Note, that since our procedure requires the existence of finite means for the computation of the MTM statistic, random variables generated from the Cauchy distribution cannot be considered, since for the latter finite moments do not exist (Casella and Berger, 2002).

${ }^{14}$ The location of the fat tail on the right side of the distribution seems somewhat counterintuitive, as strong negative returns are expected during a crisis. Nevertheless, our procedure considers identically extreme events, located at the left and/or right side of the distribution.
} 
Practically, 1,000 Monte Carlo replications of the BootS test are performed. For each Monte Carlo replication, the $f\left(M T M\left(\mathbf{Y}^{*}\right)\right)$ density is built from 10, 000 bootstrap draws from Y, and Silverman's test is set up with 1,000 bootstrap replications of $M T M$ drawn from the distribution with density $\hat{f}_{h_{c r i t}}$. The first two columns of Table 1 report the rejection frequencies of the null hypothesis of no outlier for $D G P_{1}$ and $D G P_{2}$, when using the BootS approach with $\lambda_{\alpha}=1$, and with $\lambda_{\alpha}$ set at a nominal size of $5 \%$.

\section{[Insert Table 1]}

The rejection frequencies corroborate the findings of Hall and York (2001), and Fisher and Marron (2001): the BootS test leads to an over-acceptation of the null hypothesis of no outlier when $\lambda_{\alpha}=1$. Furthermore, it is noticeable that the rejection frequency decreases as the sample size shrinks. This result is alarming for our empirical application, and indicates the need to determine an optimal $\lambda^{*}$ that is suitable for finite sample sizes. Thus, Table 1 also reports the $\lambda^{*}$ which leads to a nominal size close to $5 \%$. Interestingly, it turns out that the findings are similar for both $D G P \mathrm{~s}$ when $n=10$. Moreover, it is also noticeable that for large $n, \lambda^{*}$ converges to 1 , although the convergence is slower for the skewed distribution.

The last four columns of Table 1 deal with the rejection of the null hypothesis of no outlier when the $D G P$ s are simulated under the presence of an outlier $O$, so that $O=\bar{Y}+i * \hat{\sigma}$, where $\hat{\sigma}$ is the sample standard deviation. The size of the outlier depends proportionally on the value of $i$. Four different values of $i$ are considered, $i=3.5,4,4.5,5$. The power is corrected for size distortions, as simulations are performed with the optimal $\lambda^{*}$. It is possible to conclude that the rejection frequencies appear to be quite high in all cases. They even reach $100 \%$ in all cases where $i$ is 4.5 and 5 times the sample standard deviation.

\section{Empirical Analysis}

For the empirical application of the outlined method, we consider stock market indices of nine OECD countries (Australia, Austria, Canada, France, Germany, Italy, the Netherlands, the United Kingdom and the United States). In order to maintain homogeneity, all data are extracted from the I.F.S. database of the International Monetary Fund, and correspond to Datastream-calculated price indices of the total market, denominated in 
US Dollars. They have a monthly frequency and span the period $1973 m 1-2009 m 3$. Concerning the United States we use the Dow Jones Industrials price index for the same period, as well as the same frequency. ${ }^{15}$

\subsection{Identification of Bull and Bear Periods}

The first step of the empirical study consists of determining the bull and bear periods. To this aim, an accurate method to date turning points in the individual time series is required. We opt for a method similar to the NBER business cycle dating procedures outlined by Bry and Boschan (1971). Nevertheless, as our analysis is concerned with stock market indices, modifications to the Bry-Boschan algorithm are required. First, the original procedure replaces outliers with Spencer curve values, which has been disregarded in our specification of the algorithm. Second, in accordance with the modifications suggested by Pagan and Sossounov (2003), we dispensed with smoothing the series, and additionally we restrained the minimum length of an individual phase to four months. ${ }^{16}$

Hence, a peak of the financial cycle is defined as a local maximum in the natural logarithm of the stock market index $p_{t}$, within a window of eight months:

$$
p_{t-8}, \ldots, p_{t-1}<p_{t}>p_{t+1}, \ldots, p_{t+8}
$$

It is similarly possible to specify a trough of the cycle as a local minimum within the eight-months neighborhood of $p_{t}$ :

$$
p_{t-8}, \ldots, p_{t-1}>p_{t}<p_{t+1}, \ldots, p_{t+8}
$$

A constraint on the length of a full cycle completes the description of our financial cycle dating method. A widespread consensus in the business cycle literature indicates that a consecutive boom and bust in aggregate production should last at least fifteen months. However, due to the financial nature of our data, we set the minimum peak-topeak (trough-to-trough) period slightly longer at sixteen months, in correspondence with

\footnotetext{
${ }^{15}$ The number of countries could have been extended, but we only retain the ones, for which the number of bulls and bears are sufficient to get an acceptable size, i.e. for which at least 7 phases are observed.

${ }^{16}$ The minimum length of four months is slightly shorter than the five months minimum length imposed by the NBER. Nevertheless, it is justified by the shorter pattern of financial cycles compared to business cycles. However, imposing longer minimum phase durations would not modify our results. Results are available from the authors upon request.
} 
the window width specification in (5) and (6).

A possible alternative in the bull and bear market terminology cited inter alia in Gómez Biscarri and Pérez de Gracia (2004) is the rule-of-thumb approach by which a bull market is observed if the stock market index increases by more than $20 \%$ within a considerably short time interval, while a decline of similar magnitude is commonly associated with a bear market. Thus, the minimum peak-to-trough (trough-to-peak) constraint of four months has been revised for cases when the stock market return $\left(r_{t}=\right.$ $\Delta p_{t}$ ) exceeds $20 \%$. Hence, our dating procedure can be summarized in the following steps:

- Determine financial cycle turning points (denominated as "peak" and "trough") by identifying dates at which $p_{t}$ is higher or lower than in any other period $t$ within the eight-months neighborhood of the current observation.

- Ensure that the minimum length of the full cycle is no less than sixteen months.

- If $r_{t}$ exceeds $20 \%$, ignore the censoring rules on the length of phases.

- Enforce alternation of peaks and troughs.

Stock market indices, as well as phases are presented in Figure 1 (bull periods are marked by shaded periods). They clearly match dates reported in previous studies, and correspond to the bulls and bears associated with the oil shock, the 1987 crash, the dotcom bubble, as well as the recent sub-prime crisis. Moreover, it is noticeable that stock market indices exhibit a similar pattern across countries, confirming the relevance of the concept of financial integration.

[Insert Figure 1]

\subsection{Bull and Bear Characteristics}

The second step consists in determining the phase feature to be analyzed. The recent literature on business cycle research (e.g. Harding and Pagan, 2002, 2006, and Camacho et al., 2008) extensively describes the features associated with phases of the business cycle. Generally, the studies focus on three characteristics: the length, the amplitude and the concavity or convexity of the cycles. This exhaustive account of the cyclical behavior is, to the best of our knowledge, ignored in the financial cycles literature. One of the goals of this paper is to bridge this gap. 
Formally, the length of bulls (resp. bears) is measured by the number of months spent in the bull (resp. bear) episodes, that is, the duration between a trough and peak (resp. between a peak and trough). It is thus defined by the following statistic:

$$
D_{B u}=\sum_{t=\text { trough }}^{\text {peak }} B u_{t},
$$

and

$$
D_{B e}=\sum_{t=\text { peak }}^{\text {trough }} B e_{t},
$$

where $B u_{t}$ (resp. $B e_{t}$ ) is a binary random variable that takes the value of 1 during a bull (resp. bear) period, and it is equal to 0 otherwise.

Similarly, the amplitude of a bull (resp. bear) corresponds to the upswing (resp. downswing) of the stock market index from trough-to-peak (resp. peak-to-trough) during the bull (resp. bear) episodes. It is measured as follows:

$$
A_{B u}=\sum_{t=\text { trough }}^{\text {peak }} B u_{t} r_{t}
$$

and

$$
A_{B e}=\sum_{t=\text { peak }}^{\text {trough }} B e_{t} r_{t} .
$$

The convexity of the phase can be investigated using two measures. First, the cumulated movements measure the net gains during the phase. ${ }^{17}$ Given the first-order linear difference equation $Z_{t}=S_{t} Z_{t-1}+S_{t} r_{t}$ (where $S_{t}=B u_{t}$ during a bull phase, and $S_{t}=B e_{t}$ during a bear phase) with the starting value of $Z_{0}=0$, the cumulated returns over a bull are:

$$
C R_{B u}=\sum_{t=\text { trough }}^{\text {peak }} Z_{t}
$$

and over a bear:

\footnotetext{
${ }^{17}$ The net gain is positive during a bull and negative during a bear episode.
} 


$$
C R_{B e}=\sum_{t=p e a k}^{\text {trough }} Z_{t}
$$

The second measure of convexity has been propagated, among others, by Edwards et al. (2003), who point out that if an asset price is generated by a pure random walk, cyclical fluctuations will be close to a perfect triangle, with little or no deviations of the second derivatives from zero. However, alternative specifications are likely to produce convex or concave cycles, which provide insight into investor behavior during financial episodes. Specifically, convex bulls begin smoothly with modest price increases, while they accelerate abruptly towards the end of the phase, reflecting an element of investor impatience in the asset price accumulation. Conversely, in the case of convex bears the asset price plunges abruptly after the peak, while it calms down when approaching the trough. Naturally, concave bulls and bears exhibit the opposite dynamics. Thus, a description of the cyclical behavior robust to different specifications of the time series dynamics requires the computation of and index of excess cumulated movements, as introduced by Harding and Pagan (2002):

$$
E X_{B u}=\frac{C R_{B u}-0.5 A_{B u}-0.5\left(A_{B u} D_{B u}\right)}{D_{B u}},
$$

and

$$
E X_{B e}=\frac{C R_{B e}-0.5 A_{B e}-0.5\left(A_{B e} D_{B e}\right)}{D_{B e}} .
$$

This feature delivers the deviation of the stock market index from the triangular cycles induced by the pure random walk without drift.

Contrary to the similar studies on business cycles, we do not average these features over the number of phases. Instead, their complete historical distribution is scrutinized. Figure 2 illustrates the features defined above for a particular bull and bear phase of the French stock market.

\section{[Insert Figure 2]}

Typically, our database allows us to observe around ten phases (that is, ten bulls and ten bears) and their corresponding features. Even if the sample is small, it nevertheless allows us to test for outliers in the distribution of the features, which we can associate with exceptional episodes in the financial cycle. 


\subsection{Detecting Exceptional Bulls and Bears via the BootS Ap- proach}

Once the cyclical periods of the stock market indices, as well as their features, are determined, the final step consists in applying the new non-parametric approach described in Section 2. It allows us to determine the presence outlier(s) in the historical distribution of the financial cycle characteristics, as well as to identify the corresponding phase.

Tables 2 and 3 gather the results of the BootS tests. In the first row p-values are reported for the BootS test with the optimal, size-adjusted $\lambda^{*}$, corresponding to the respective number of observations. ${ }^{18}$ If the respective p-value is higher than $5 \%$, it signifies that no outlier is detected. On the contrary, when it is below $5 \%$, the presence of an outlier is supported, and the BootS test is repeated for the same historical distribution, but without this outlier. The procedure stops when no more outlier is found. Therefore, the number of outliers is equal to the number of p-values reported minus one. The rank of the last bull in the distribution is also reported between brackets. In Table 3 the last bear is censored, as it is still ongoing.

[Insert Tables 2 and 3]

Commencing with the detection of exceptional bulls, it turns out that these phases are regular with respect to all features for Australia, France, Italy and the Netherlands. In the case of the United Kingdom and the United States an extreme bull phase is detected in the second half of the $1980 \mathrm{~s}$, while for Austria we find an irregular bull episode in the early $1990 \mathrm{~s}$. These findings support the view that the returns earned on the stock markets during these decades were unusual. For Germany and the United States an exceptional period of rise is detected in the early $2000 \mathrm{~s}$, which can be associated with the dotcom bubble. This bull typically exhibits an abnormally long duration (between 7 and 10 years), moreover, for the United States it is exceptional with respect to all features considered. This outcome stresses that the accumulation of the dotcom bubble constitutes a period during which extremely advantageous positions could be taken by investors. On the contrary, the latest bull period does not appear to be different from the past ones, even though it is ranked as the strongest for Australia, Austria, the United Kingdom and the

\footnotetext{
${ }^{18}$ We report the results for $\lambda_{\alpha}=1$ in Appendix 1, in Tables 6 to 8. Results are robust and do not exhibit major discrepancies.
} 
United States, for various features considered. The only noticeable exception is Canada, where the last bull presents extreme patterns, preceding a future severe explosion.

Similarly, Table 3 indicates that all bears are issued from the same underlying Data Generating Processes in Australia, Austria, Canada, Italy, the Netherlands and the United States. The bursting of the dotcom bubble generated an exceptional bear in Germany, exhibiting an irregular amplitude and excess characteristic. The excess feature is also exceptional in the United Kingdom after the first oil shock, while the second oil shock produced unusual cumulated returns in France, and a particularly short bear in Germany.

\subsection{A Closer Look at the Sub-Prime Crisis}

The previous analysis is performed without considering the ongoing bear period generated by the sub-prime crisis. It is actually difficult to judge at this stage if it will provoke an exceptional collapse of the stock markets worldwide. First, the crisis is most probably not yet over, and the stock markets have not yet reached their cyclical trough. Second, political authorities may again intervene and support the stock market indices by directly injecting liquidity, or by supporting particular sectors, as the car industry in the United States. It is nevertheless interesting to analyze the exceptional pattern of the sub-prime bear today, i.e. in March, 2009. The sequential BootS tests are thus performed without censoring for the last bear, hence assuming that the trough was reached on $2009 \mathrm{~m} 3$. Results are reported in Table 4.

\section{[Insert Table 4]}

The results are, of course, conditional on the ongoing nature of the crisis. Clearly, the duration characteristic is the less interesting one. Stock markets have been first affected by the sub-prime crisis quite recently (mid-2007), thus, this feature can not appear exceptional. The results are mixed and, interestingly, the last bear turns out to be exceptional for only four out of nine countries: Austria, the Netherlands, the United Kingdom, and the United States. ${ }^{19}$ For the remainder of the countries the decline remains in line with the previous bears. To contrast this result, and to motivate the anxiety of market practitioners, Table 4 also shows that the present bear is already the most severe in terms of amplitude, cumulated returns, and the excess feature for the majority of

\footnotetext{
${ }^{19}$ In case of the U.S. the last bear has become an outlier in March, 2009. Before this date, it still appears in line with the previous bears.
} 
the countries. ${ }^{20}$ Nevertheless, for most of the countries the sub-prime bear can not be considered as an outlier, and thus the exceptional character in not supported.

The exceptional bulls and bears that occurred, according to the sequential method, on the analyzed stock markets since 1973, are reported in Figure 3 (exceptional bulls (resp. bears) are marked in grey (resp. black)).

\section{[Insert Figure 3]}

As the trough of the bear has still not been reached, it may be interesting to determine the thresholds beyond which the bear will become exceptional. This normative exercise provides a sort of alarm for investors: If the thresholds are not crossed over, then they can conclude that the bear exhibits a regular pattern, and thus can base their decisions on a traditional chartist method. On the contrary, if the phase would become exceptional, i.e. not in line with the historical distribution, then traditional inference would not apply anymore.

Table 5 reports the value taken by the features for the ongoing bear phase in $2009 m 3$. It also gathers the historical mean $(\bar{X}($ bear $))$ and the standard deviation $($ std(bear $))$ once the outliers are removed. Thus, following the terminology of Pagan and Sossounov (2003), these statistics can be interpreted as the characteristics of the usual financial phases. It is noticeable, that since these statistics are similar across countries, the idea of international financial integration is again supported. Table 5 also shows the thresholds beyond which the characteristics would be an outlier according the the BootS approach at a nominal size of $5 \%$.

\section{[Insert Table 5]}

The thresholds beyond which the respective feature will become extraordinary are still far away from the observed values (except for the cases when the thresholds have been reached, i.e. Austria, Netherlands, U.K., and U.S.). In most cases, the ratios between the observed feature and the threshold are not far from 0.5. Thus, our normative exercise indicates that the probability of a feature crossing the threshold in the short run, signaling an exceptional bear phase, is moderate. Therefore, our findings should soothe investors who are fearing that the sub-prime crisis is paving the way for an exceptional bear period worldwide, which would invalidate the traditional decision schemes of international portfolio allocation.

\footnotetext{
${ }^{20}$ Its rank lies in the top $50 \%$ of the historical distribution whatever the country, and is even the largest in 21 cases out of 36 .
} 


\section{Conclusion}

This paper contributes to the growing literature on stock market bulls and bears in several aspects. First, it completes the Reinhart and Rogoff (2008) study by developing a cross-country analysis of the sub-prime crisis. Second, it extends the description of financial cycles by going beyond solely the duration feature, and considers also the amplitude, as well as the cumulated returns, and the excess returns. Third, a methodological improvement is provided by a new, non-parametric test for outliers, which elaborates on Singh and Xie (2003) and Silverman (1981). Based on this procedure, it is possible to detect the exceptional bulls and bears that occurred since 1973. Moreover, a normative analysis sheds some light on the exceptional patterns of the ongoing sub-prime crisis. Our outcomes are mixed and, up-to-date, they do not support the idea of a worldwide crisis. The sub-prime bear exhibits exceptional characteristics for Austria, the Netherlands, the United Kingdom, and the United States, however, it remains in line with previous bear markets for the remainder of the analyzed countries. Furthermore, the results indicate that the chance of a feature of the financial cycle crossing the threshold in the short run is moderate.

Nevertheless, several words of caution are necessary. First, even though, according to the results of this paper, the cross-country effects of the sub-prime crisis on stock market cycles are mixed, it is not said that the sub-prime turmoil cannot be considered a global financial crisis in a wider sense. It is in our opinion unambiguously a banking crisis. Therefore, it is likely that sectoral stock indices (in particular the banking index) will present more extreme cyclical patterns, than those of aggregate national indices. Similarly, individual shares, as the ones associated with financial companies, have experienced exceptional decline since the beginning of the sub-prime bear. Second, this paper does not investigate the real consequences of the sub-prime crisis on business cycles, as it exclusively focuses on stock market bulls and bears. While being an interesting research topic, our choice is motivated by the fact that industrial production or GDP are subject to revision up to one and a half years, which is not the case for stock market indices. Besides, the transmission of the crisis to real variables will be delayed, whereas the reaction of financial markets is extremely rapid. Nevertheless, in Appendix 2 a preliminary investigation of business cycle phases is performed using Industrial Production indices. Applying the sequential BootS approach, it turns out that the last recession is not extreme, whatever the country considered. Nevertheless, a more in-depth analysis would 
be required to investigate this issue. Third, it has to be stressed that the results of the normative analysis are conditional on the information available in March, 2009. Even if the results are robust to the recent variation of stock market indices, they do not preclude future crashes on stock markets. In such a case the sub-prime bear could become exceptional.

Subject to the issues addressed above, this paper corroborates the findings of Reinhart and Rogoff (2008), as it is possible to induce that this crisis does share important similarities with other financial turmoils. It also completes their analysis, stressing the heterogenous nature of the crisis across countries. Several countries (Austria, the Netherlands, the United Kingdom, and the United States) are facing an exceptional bear, while for the others the current decline is in line with the historical distribution of bear stock markets. 


\section{References}

[1] Barnett, V. And Lewis, T. (1994). Outliers in Statistical Data. Wiley, 3rd edition. Wiley Series in Probability and Statistics.

[2] Barsky, R. B. And De Long, J. B. (1990). Bull and Bear Markets in the Twentieth Century. The Journal of Economic History 2, 265-281.

[3] Bry, G. And Boschan, C. (1971). Cyclical Analysis of Time Series: Selected Procedures and Computer Programs. NBER, New York.

[4] Camacho, M., Perez-Quiros, G. And Saiz, L. (2008). Do European Business Cycles Look Like One? Journal of Economic Dynamics and Control 32, 2165-2190.

[5] Candelon, B., Piplack, J. and Straetmans, S. (2008). On Measuring Synchronization of Bulls and Bears: The Case of East Asia. Journal of Banking and Finance 32(6), 1022-1035.

[6] Casella, G. and Berger, R. L. (2002). Statistical Inference. Duxbury Press, 2nd edition. Duxbury Advanced Series.

[7] Chen, S.-S. (2009). Predicting the Bear Stock Market: Macroeconomic Variables as Leading Indicators. Journal of Banking and Finance 33(2), 211-223.

[8] Coakley, J. and Fuertes, A. M. (2006). Valuation Ratios and Price Deviations from Fundamentals. Journal of Banking and Finance 30, 2325-2346.

[9] Edwards, S., Gómez Biscarri, J. And PÉrez de Gracia, H. F. (2003). Stock Market Cycles, Financial Liberalization and Volatility. Journal of International Money and Finance 22, 925-955.

[10] Efron, B. (1979). Bootsptrap Methods: Another Look at the Jackknife. The Annals of Statistics 7(1), 1-26.

[11] Fisher, N. I. And Marron, J. S. (2001). Mode Testing via the Excess Mass Estimate. Biometrika 88(2), 499-517.

[12] Gómez Biscarri, J. And PÉrez de Gracia, H. F. (2002). Bulls and Bears: Lessons from some European Countries. Working paper. 
[13] Gómez Biscarri, J. And Pérez de Gracia, H. F. (2004). Stock Market Cycles and Stock Market Development in Spain. Spanish Economic Review 6, 127-151.

[14] Hall, P. And York, M. (2001). On the Calibration of Silverman's Test for Multimodality. Statistica Sinica 11, 515-536.

[15] Harding, D. And Pagan, A. (2002). Dissecting the Cycle: a Methodological Investigation. Journal of Monetary Economics 49, 365-381.

[16] Harding, D. And Pagan, A. (2006). Synchronization of Cycles. Journal of Econometrics $132,59-79$.

[17] Hartmann, P., Straetmans, S., De Vries, C.G. (2003). A global perspective on extreme currency linkages. In: Hunter, W.C., Kaufman, G.G., Pomerleano, M. (Eds.), Asset Price Bubbles: The Implications for Monetary, Regulatory and International Policies. MIT Press, Cambridge (MA), 361-382.

[18] Jansen, D.W., De VRIEs, C.G. (1991). On the frequency of large stock returns: putting booms and busts into perspective. Review of Economics and Statistics 73, $19-24$.

[19] Longin, F.M. (1996). The asymptotic distribution of extreme stock market returns. Journal of Business 69, 383-408.

[20] Lux, T. (1996). The stable Paretian Hypothesis and the frequency of large returns: an examination of major German stocks. Applied Financial Economics 6(6), 463-475.

[21] Pagan, A.P., Sossounov, K.A. (2003). A Simple Framework for Analysing Bull and Bear Markets. Journal of Applied Econometrics 18, 233-246.

[22] Reinhart, C. M. and Rogoff, K. S. (2008). Is the 2007 US Sub-prime Financial Crisis So Different? An International Historical Comparison. American Economic Review 98(2), 339-344.

[23] ShILleR, R. J. (2000). Irrational Exuberance. Princeton University Press, Princeton.

[24] Siegel, J. J. (1998). Stock for the Long Run. McGraw-Hill, New York.

[25] Silverman, B. W. (1981). Using Kernel Density Estimates to Investigate Multimodality. Journal R. Statist. Soc. B 43(1), 97-99. 
[26] Singh, K. And XIE, M. (2003). Bootlier-Plot - Bootstrap Based Outlier Detection Plot. Sankhya: The Indian Journal of Statistics 65(3), 532-559.

[27] Summers, L. H. (1986). Does the Stock Market Rationally Reflect Fundamental Values? Journal of Finance 41, 591-602. 
Appendix 1: Robustness check for $\lambda_{\alpha}=1$

[Insert Tables 6 to 8] 


\section{Appendix 2: Exceptional cyclical phases in industrial production}

The recent sub-prime crisis has had severe repercussions on aggregate economic activity. In order to assess the consequences of the crisis for the business cycle, we applied the sequential approach on industrial production (IP) indices. As documented by Camacho et al. (2008), IP indices are superior compared to quarterly GDP series, in that they are more homogenous across countries and are available at a monthly frequency. Moreover, the data covers the period 1958m1-2008m12, which is long enough to extract the number of cycles which is appropriate for our analysis.

Specifically, we considered seasonally adjusted IP indices $(2000=100)$ for Austria, Canada, France, Germany, Italy, Netherlands, the United Kingdom and the United States. $^{21}$ The data has been retrieved from the I.F.S. database of the International Monetary Fund. In order to obtain business cycle turning points, we applied the original Bry and Boschan (1971) algorithm adapted for monthly data, with minimum peak-totrough (trough-to-peak) constraint of five months, and minimum peak-to-peak (troughto-trough) periods of fifteen months.

The results of the BootS tests for the IP indices are reported in Tables 9 and 10.

[Insert Tables 9 to 10$]$

${ }^{21}$ The respective data were unavailable in the case of Australia. 


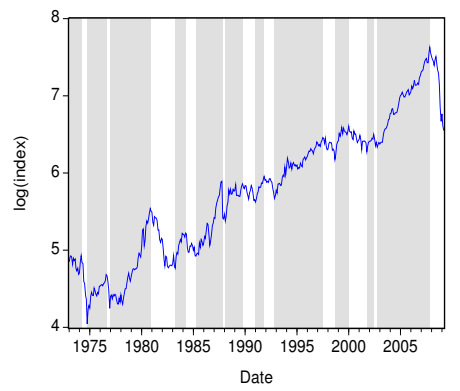

(a) Australia

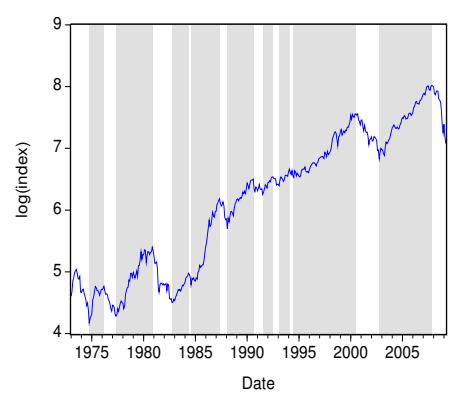

(d) France

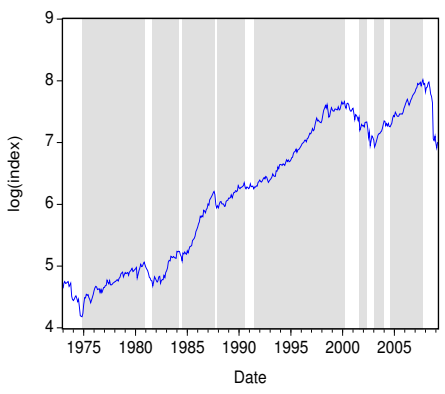

(g) Netherlands

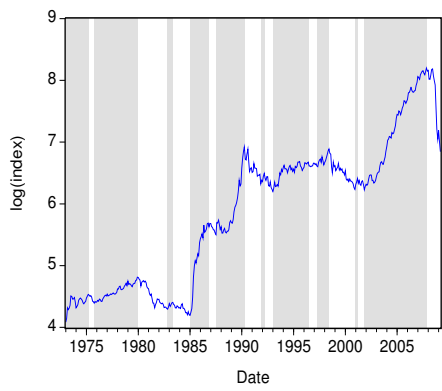

(b) Austria

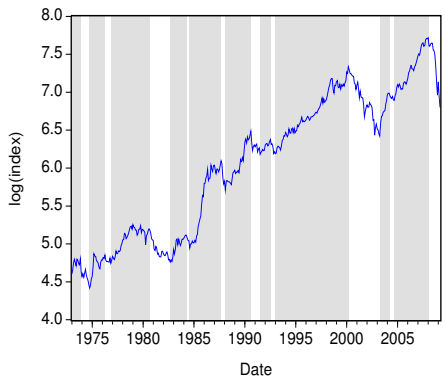

(e) Germany

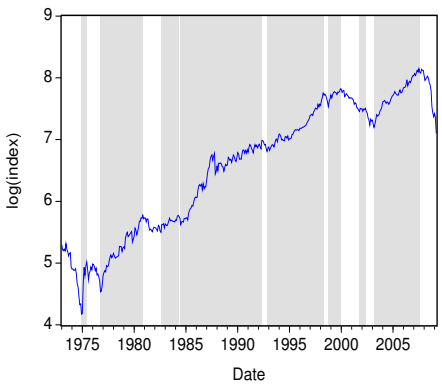

(h) UK

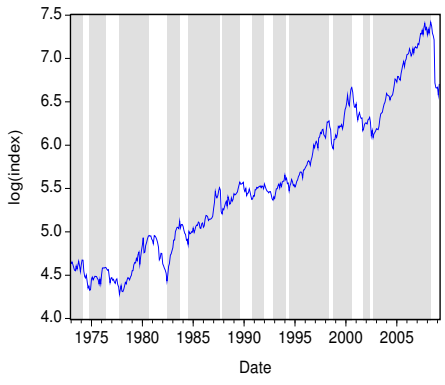

(c) Canada

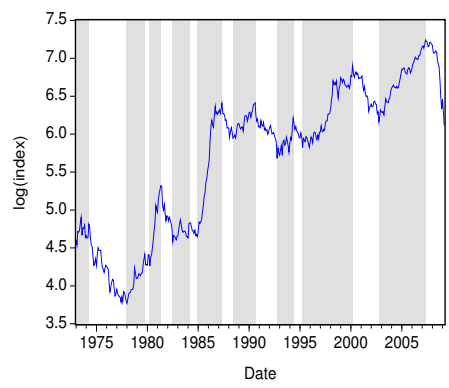

(f) Italy

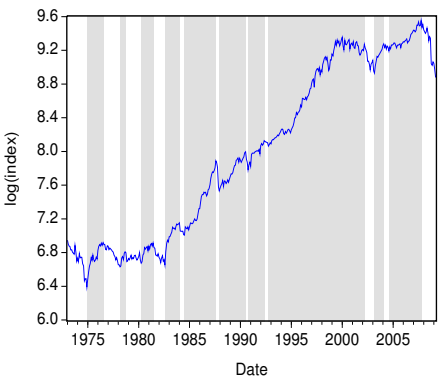

(i) US

Figure 1: Bulls and Bears Classification of Stock Market Indices

Note: Datastream-calculated price indices of the total stock market, and the Dow Jones Industrials index, spanning 1973m1-2009m3, retrieved from the I.F.S. database of the International Monetary Fund. Bull (resp. bear) periods are marked by shaded (resp. white) periods. 


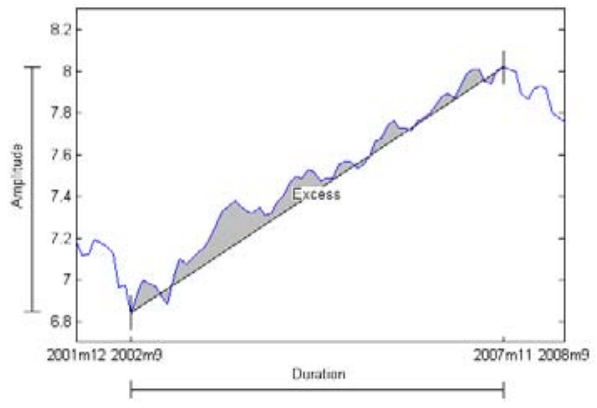

(a) Bull

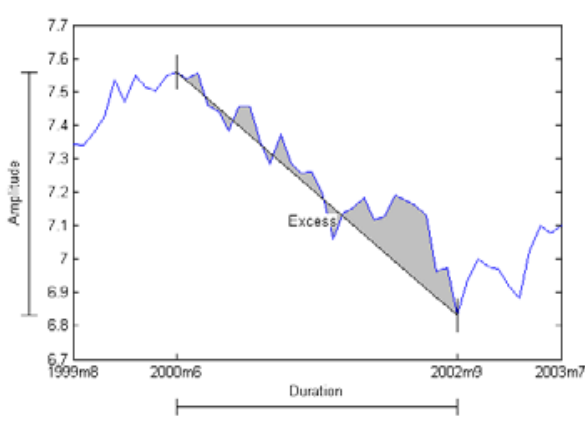

(b) Bear

Figure 2: Bulls and Bears Features

Note: Bulls and bears characteristics illustrated for a particular bull and bear phase of the French stock market (the grey area corresponds to the index of excess cumulated movements).

Table 1: Size and power analysis

\begin{tabular}{|c|c|c|c|c|c|c|}
\hline \multicolumn{7}{|c|}{$D G P_{1}: N(0,1)$} \\
\hline & Rejec. freq. & $\lambda_{\alpha}$ & $i=3.5$ & $i=4$ & $i=4.5$ & $i=5$ \\
\hline \multirow[t]{2}{*}{$n=10$} & 0.00 & 1 & 0.22 & 1 & 1 & 1 \\
\hline & 0.05 & 1.137 & 0.96 & 1 & 1 & 1 \\
\hline \multirow[t]{2}{*}{$n=100$} & 0.01 & 1 & 1 & 1 & 1 & 1 \\
\hline & 0.05 & 1.021 & 1 & 1 & 1 & 1 \\
\hline \multicolumn{7}{|c|}{$D G P_{2}:$ Student $-t$} \\
\hline & Rejec. freq. & $\lambda_{\alpha}$ & $i=3.5$ & $i=4$ & $i=4.5$ & $i=5$ \\
\hline \multirow[t]{2}{*}{$n=10$} & 0.00 & 1 & 0.19 & 0.98 & 1 & 1 \\
\hline & 0.05 & 1.134 & 0.41 & 1 & 1 & 1 \\
\hline \multirow[t]{2}{*}{$n=100$} & 0.04 & 1 & 1 & 1 & 1 & 1 \\
\hline & 0.05 & 1.070 & 1 & 1 & 1 & 1 \\
\hline
\end{tabular}

Note: The first two columns of Table 1 report the rejection frequencies of the null hypothesis of no outlier for $D G P_{1}$ and $D G P_{2}$, when using the BootS approach with $\lambda_{\alpha}=1$, and with $\lambda_{\alpha}$ set at a nominal size of $5 \%$. 1,000 Monte Carlo replications of the BootS are performed. For each Monte Carlo replication, the $f\left(M T M\left(\mathbf{Y}^{*}\right)\right)$ density is built from 10,000 bootstrap draws from Y , and Silverman's test is set up with 1,000 bootstrap replications of $M T M$ drawn from the distribution with density $\hat{f}_{h_{c r i t}}$. The last four columns of Table 1 deal with the rejection of the null hypothesis of no outlier when the DGPs are simulated under the presence of an outlier (with outliers specified as values corresponding to the mean plus $i$ times the size of the sample standard deviation $\hat{\sigma}$ ). The power is corrected for size distortions, as simulations are performed with the optimal $\lambda^{*}$. 


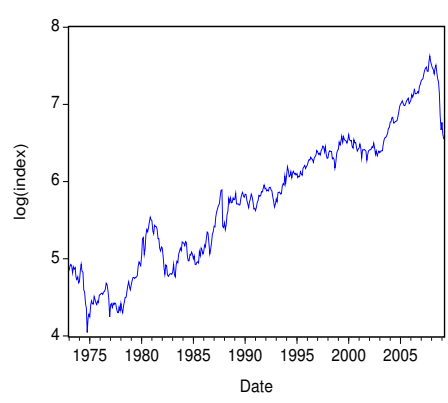

(a) Australia

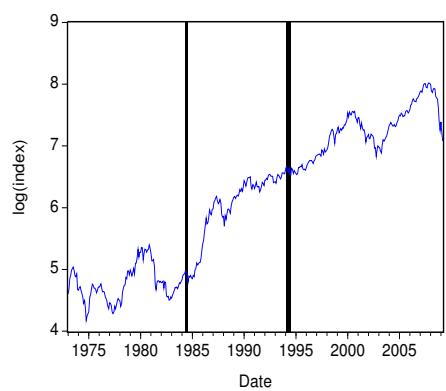

(d) France

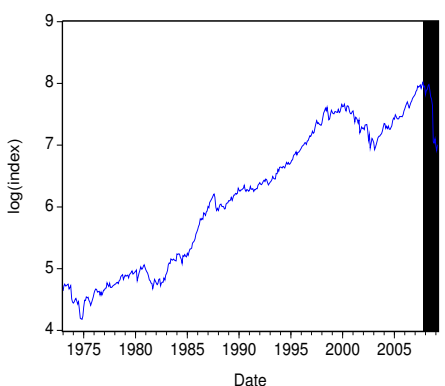

(g) Netherlands

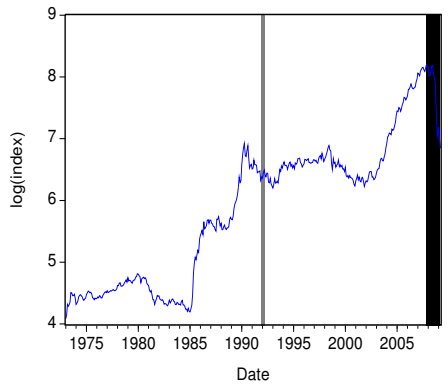

(b) Austria

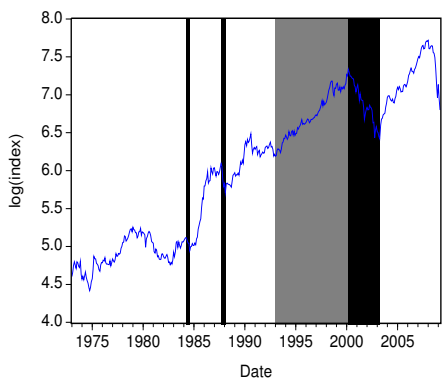

(e) Germany

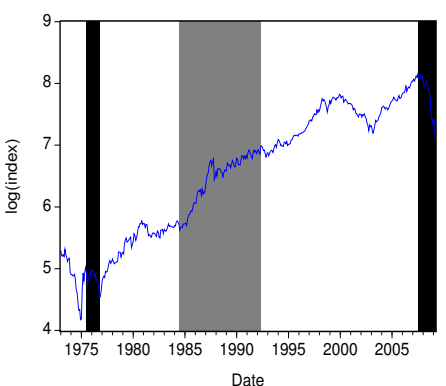

(h) UK

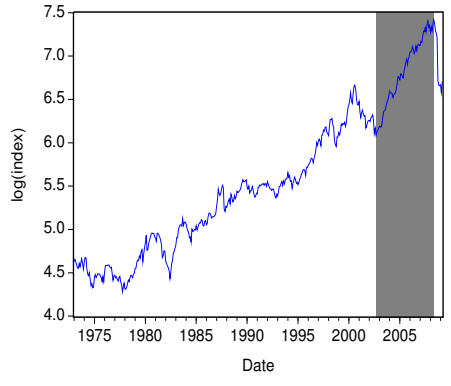

(c) Canada

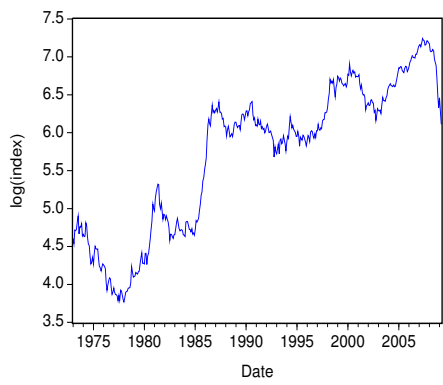

(f) Italy

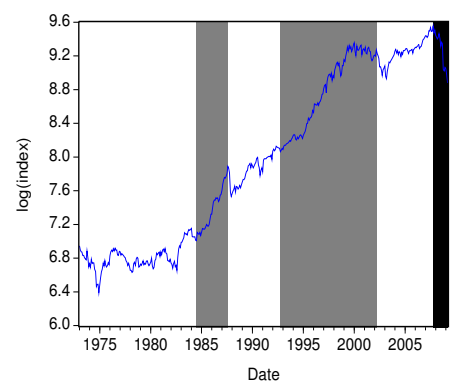

(i) US

Figure 3: Exceptional Bulls and Bears of Stock Market Indices

Note: Exceptional bulls and bears that occurred, according to the sequential method, on the analyzed stock markets during 1973m1-2009m3. Exceptional bulls (resp. bears) are marked in grey (resp. black). 


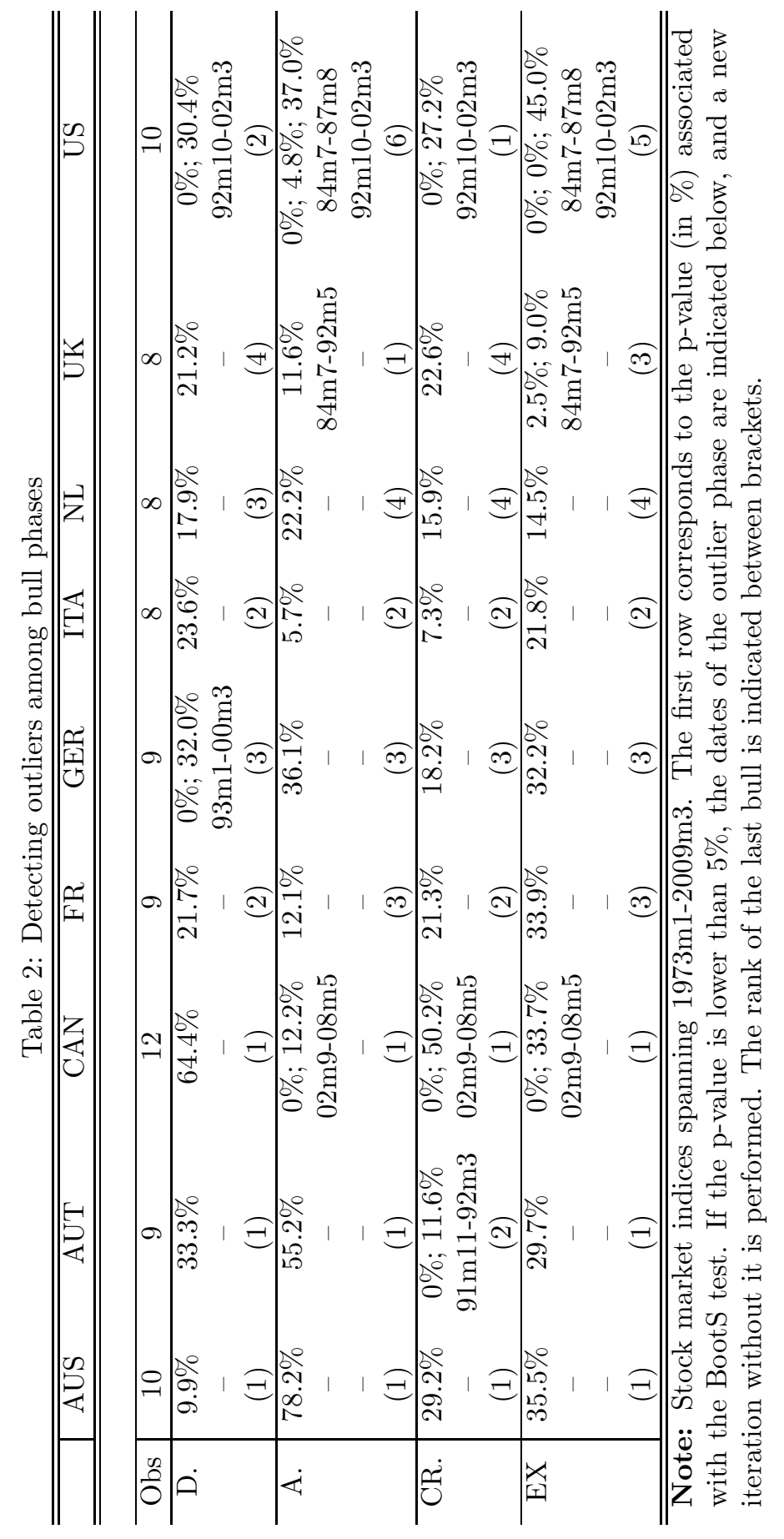




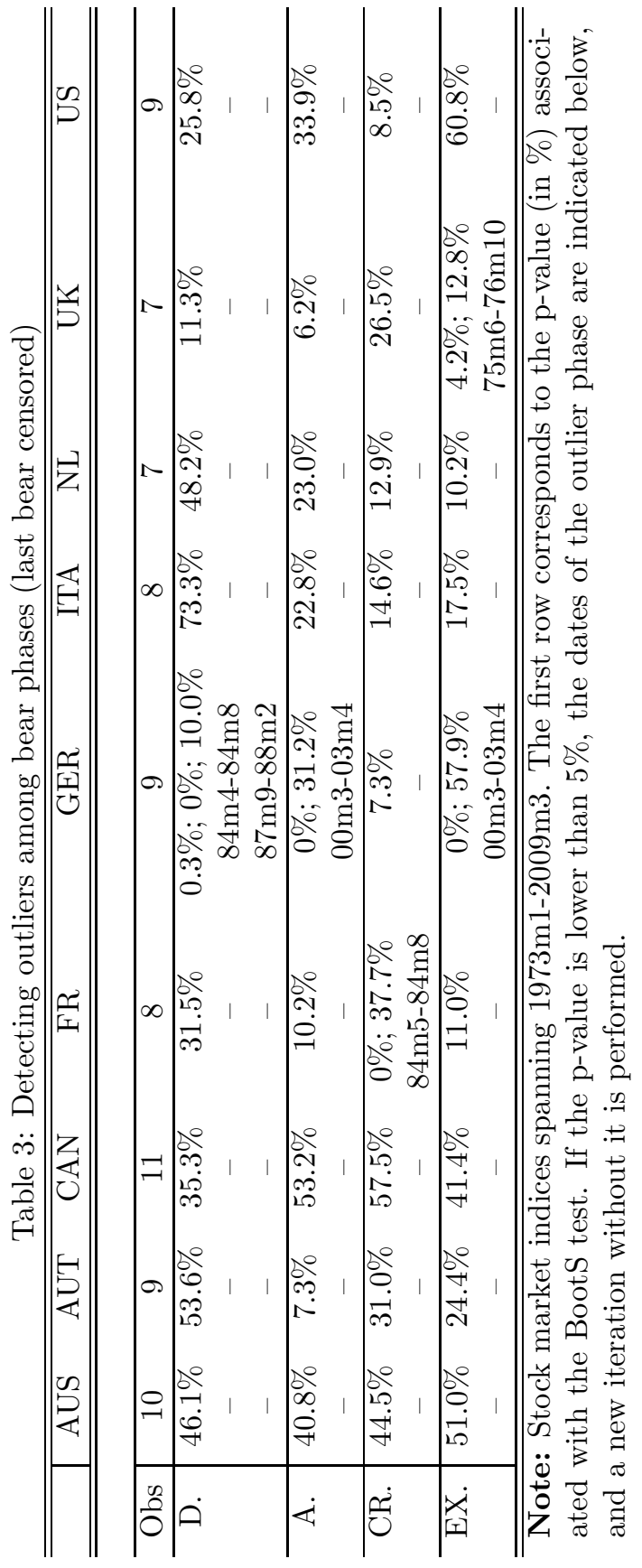




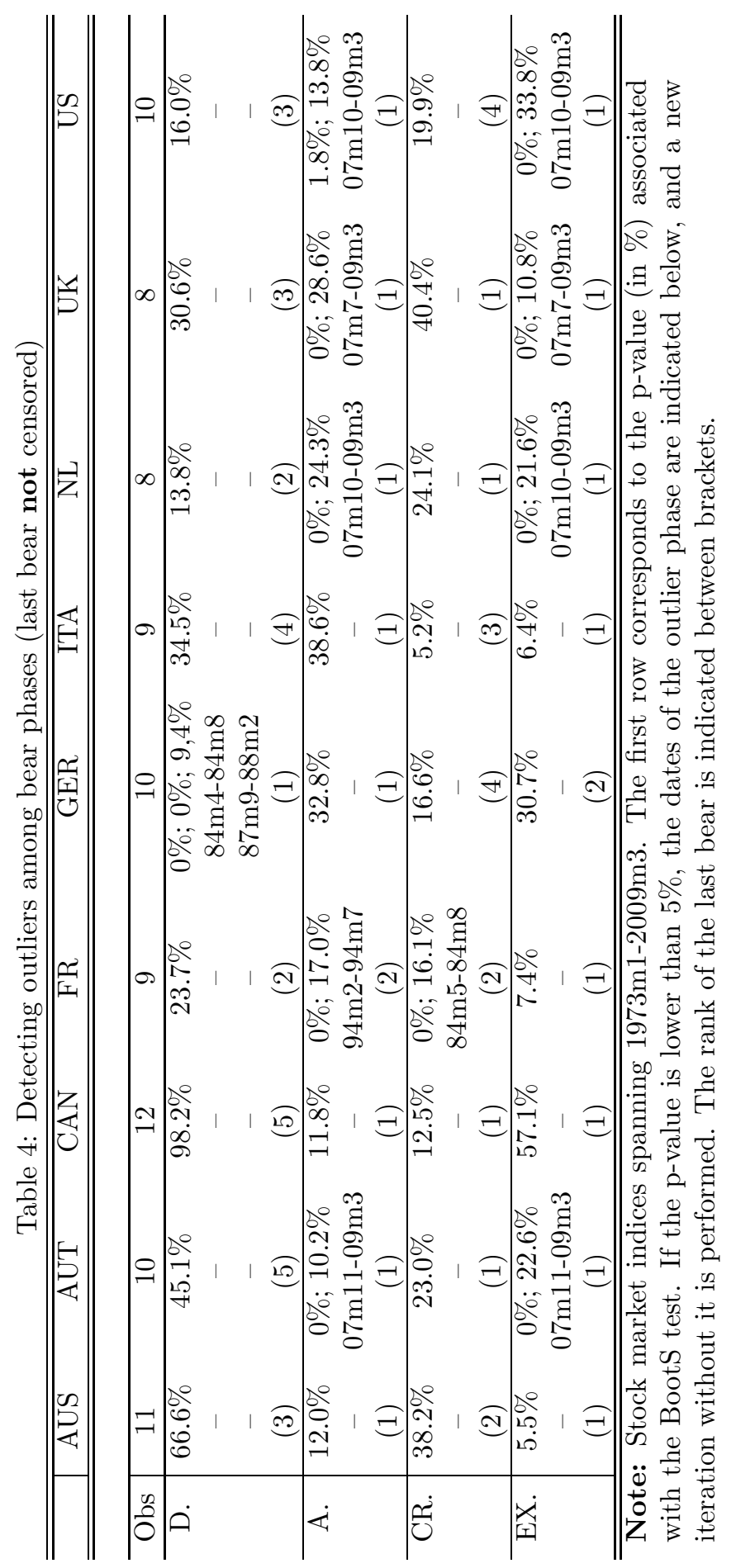




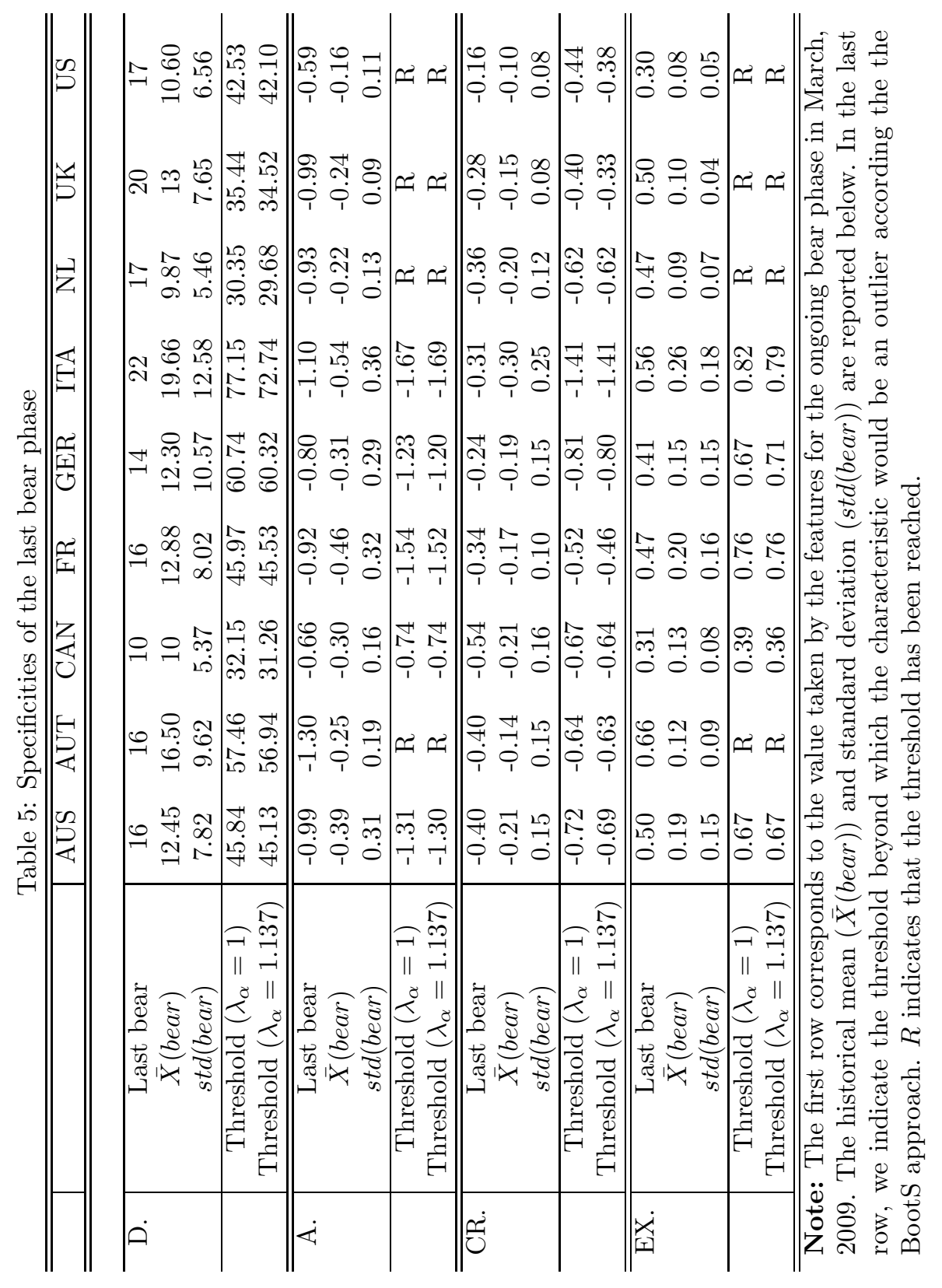




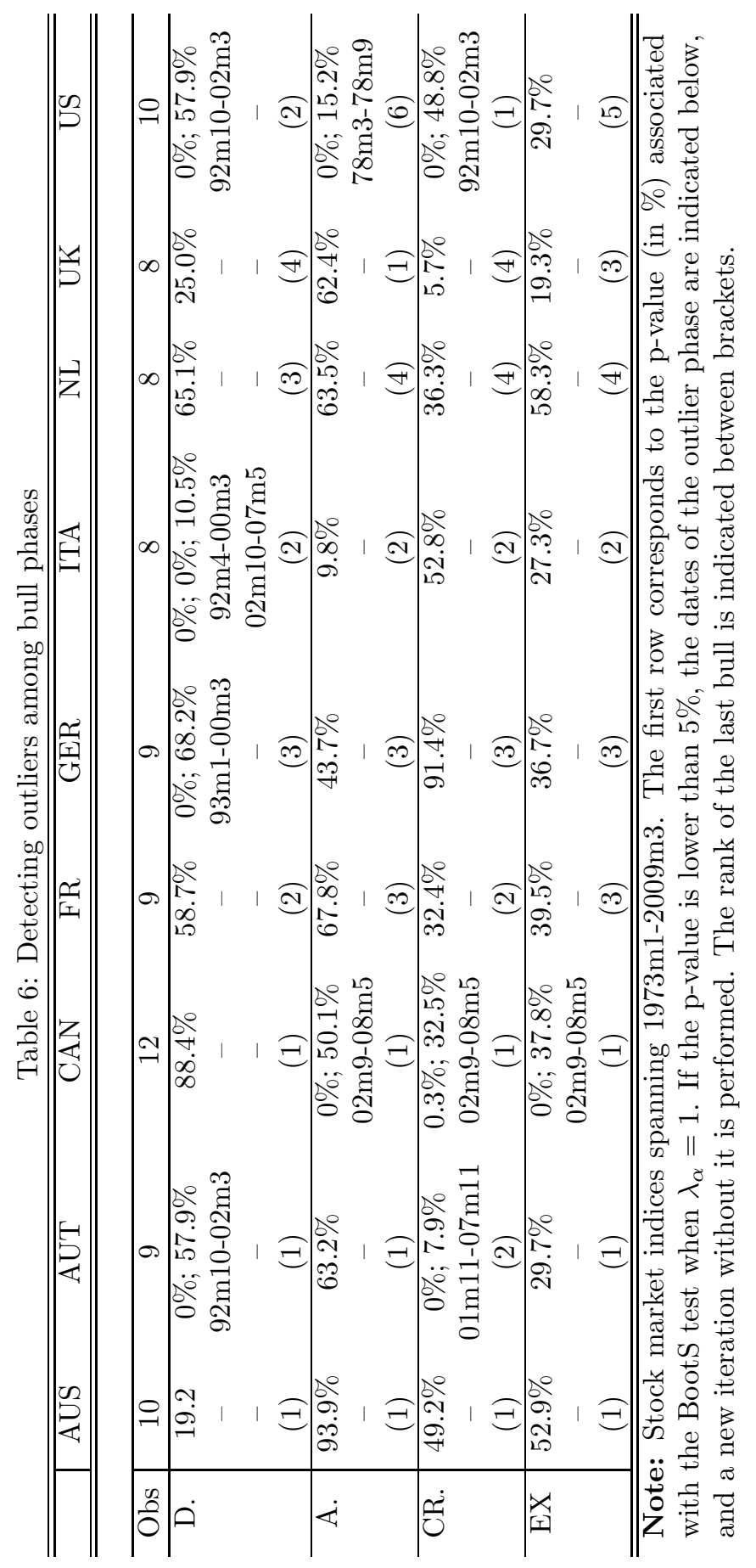




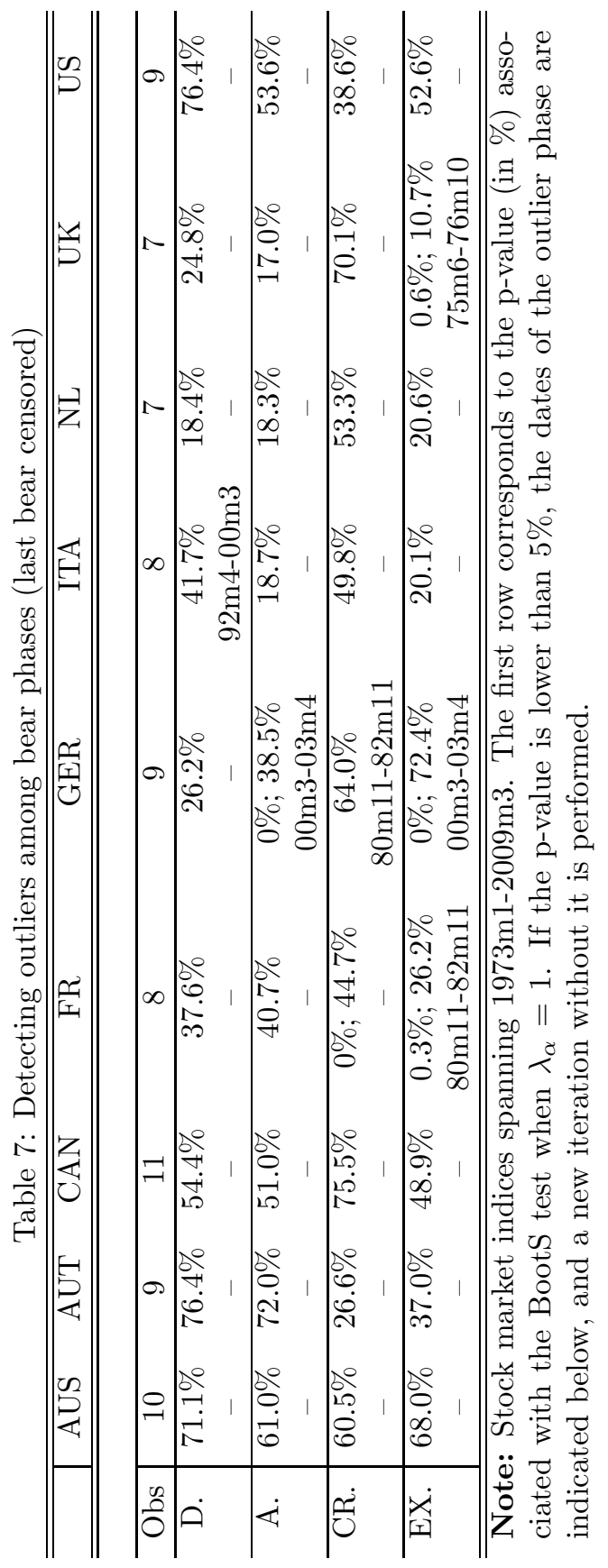




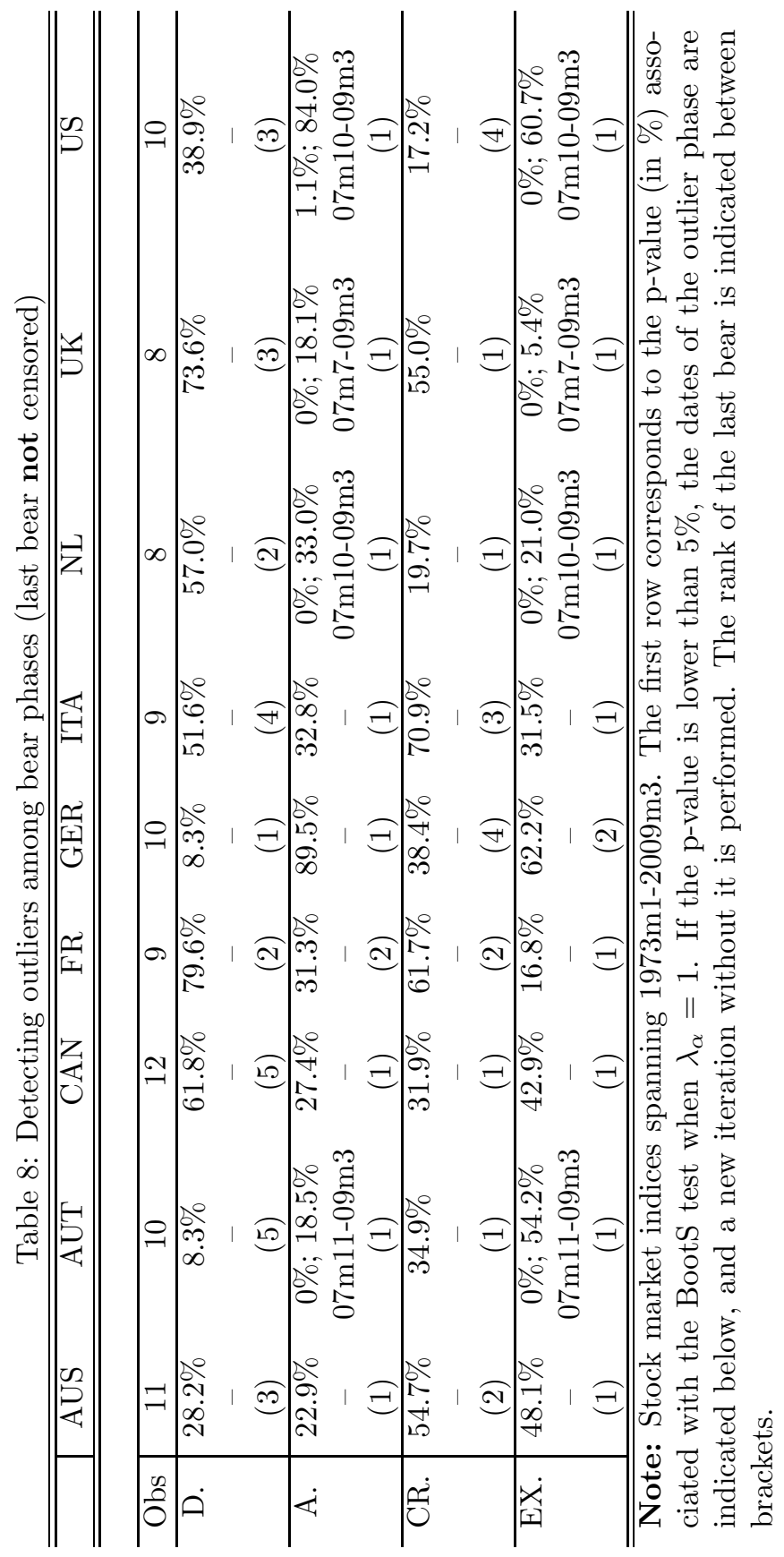




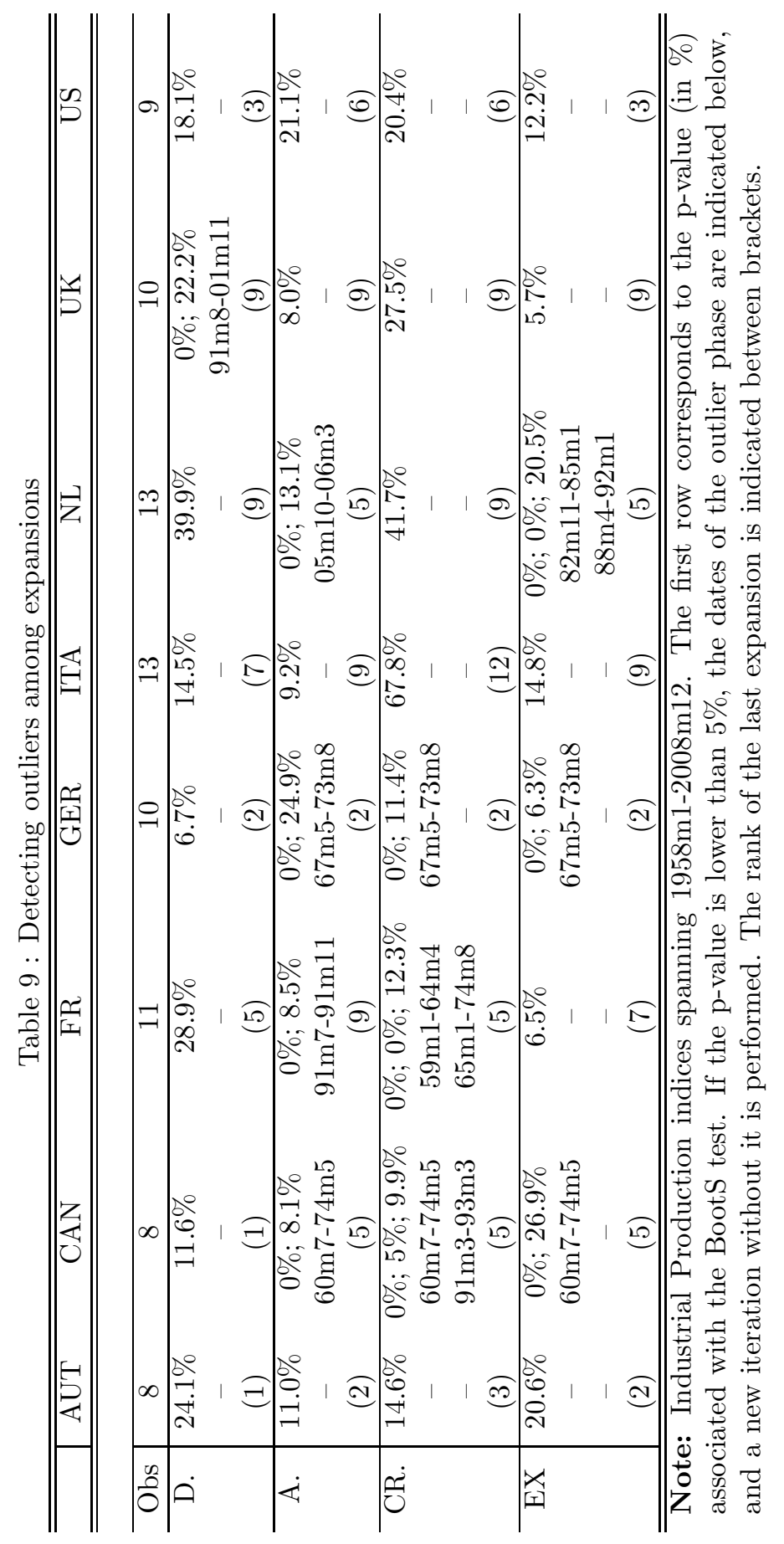




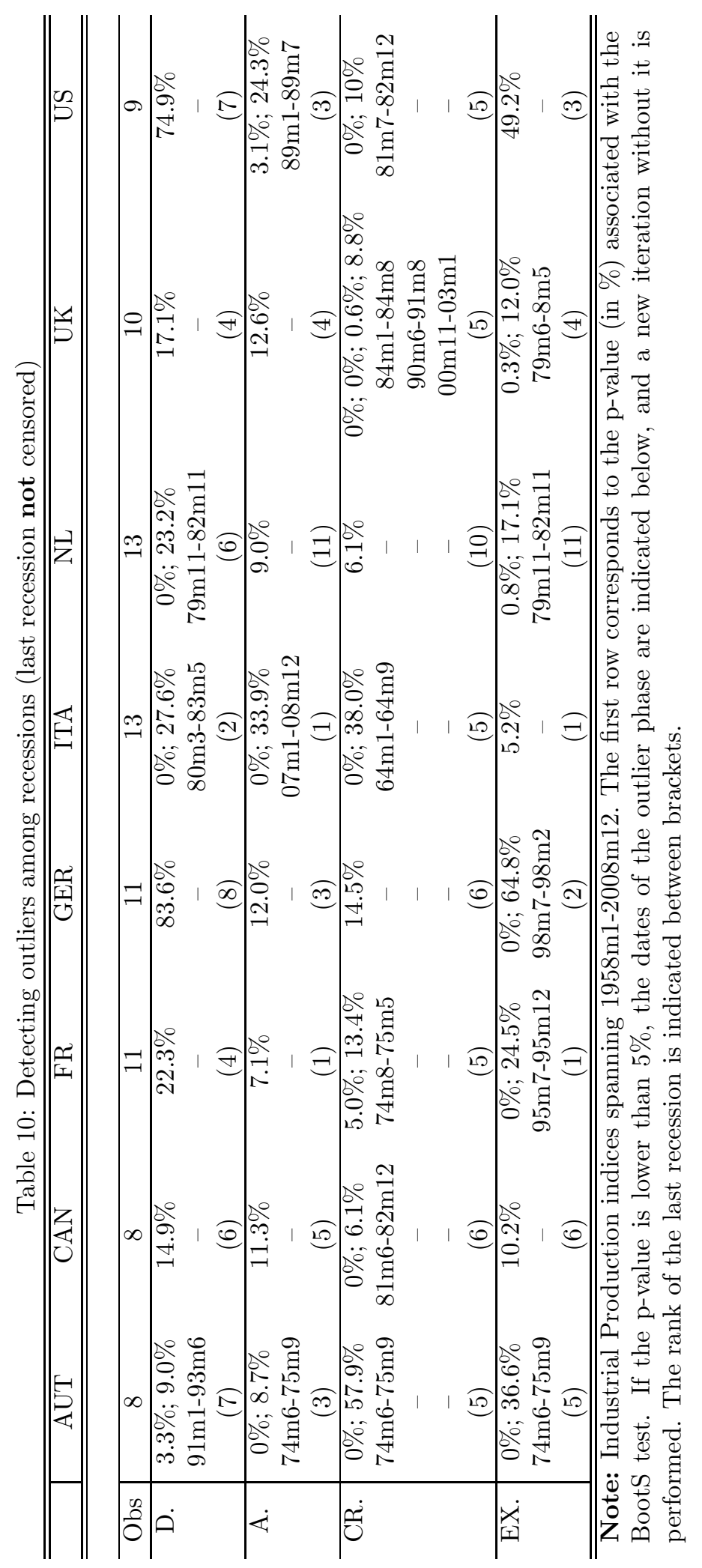

